\title{
Aminoacetonitrile characterization in astrophysical-like conditions
}

\author{
F. Borget, G. Danger, F. Duvernay, M. Chomat, V. Vinogradoff, P. Theulé, and T. Chiavassa
}

\begin{abstract}
Aix-Marseille Université et CNRS, Laboratoire de Physique des Interactions Ioniques et Moléculaires, UMR 7345, Centre de St-Jérôme, case 252, Avenue Escadrille Normandie-Niémen, 13397 Marseille Cedex 20, France

e-mail: Fabien.Borget@univ-amu.fr
\end{abstract}

Received 2 February 2012 / Accepted 23 March 2012

\section{ABSTRACT}

\begin{abstract}
Context. Aminoacetonitrile (AAN) has been detected in 2008 in the hot core SgrB2. This molecule is of particular interest because it is a central molecule in the Strecker synthesis of amino acids. This molecule can be formed from methanimine $\left(\mathrm{CH}_{2} \mathrm{NH}\right)$, ammonia $\left(\mathrm{NH}_{3}\right)$ and hydrogen cyanide $(\mathrm{HCN})$ in astrophysical icy conditions. Nevertheless, few studies exist about its infrared (IR) identification or its astrophysical characterization.

Aims. We present in this study a characterization of the pure solid AAN and when it is diluted in water to study the influence of $\mathrm{H}_{2} \mathrm{O}$ on the main IR features of AAN. The reactivity with $\mathrm{CO}_{2}$ and its photoreactivity are also studied and the main products were characterized.

Methods. Fourier transformed infrared (FTIR) spectroscopy of AAN molecular ice was performed in the 10-300 K temperature range. We used temperature-programmed desorption coupled with mass spectrometry detection techniques to evaluate the desorption energy value. The influence of water was studied by quantitative FTIR spectroscopy and the main reaction and photochemical products were identified by FTIR spectroscopy.

Results. We determined that in our experimental conditions, the IR limit of AAN detection in the water ice is about $1 \times 10^{16}$ molecule $\mathrm{cm}^{-2}$, which means that the AAN detection is almost impossible within the icy mantle of interstellar grains. The desorption energy of pure solid AAN is of $63.7 \mathrm{~kJ} \mathrm{~mol}^{-1}$ with $v_{0}$ to $10^{28}$ molecule $\mathrm{cm}^{-2} \mathrm{~s}^{-1}$, which implies that the presence of this molecule in the gas phase is only possible in hot cores. The glycine (Gly) formation from the AAN through the last step of the Strecker synthesis seems to be impossible in astrophysical-like conditions. Furthermore, AAN is photoresistant to vacuum ultra-violet radiation, which emphasizes the fact that AAN can be considered as a Gly reservoir molecule.
\end{abstract}

Key words. astrochemistry - ISM: molecules - dust, extinction - molecular processes - molecular data - methods: laboratory

\section{Introduction}

Aminoacetonitrile (AAN) is a central molecule in the Strecker synthesis of Glycine (Gly) (Elsila et al. 2007). Aminoacetonitrile is then considered as one of the best ways to form amino acids in prebiotic environment and more especially in the UreyMiller-type experiments (Miller 1953). The Strecker synthesis implies the reaction of $\mathrm{NH}_{3}$ with an aldehyde (formaldehyde for the Gly formation) in presence of hydrogen cyanide (HCN). The first step of this reaction is the formation of an aminoalcohol that is then dehydrated in imine. Those reactions are easily observed in liquid phase, but were recently confirmed in astrophysical-like conditions (Bossa et al. 2009b; Duvernay et al. 2010; Vinogradoff et al. 2011, 2012). This molecule can react with $\mathrm{HCN}$ and form aminoacetonitrile, yielding Gly by hydrolysis. In liquid phase, AAN can produce hydantoine and $\mathrm{N}$-carbamoylaminoacid (CCA) following the Bucherer-Bergs reaction (Commeyras et al. 2004; de Marcellus et al. 2011). This CCA leads to amino acid polymerization in aqueous environments (Commeyras et al. 2004; Danger et al. 2006).

AAN is also of great interest because its detection in the gas phase of interstellar medium (ISM) was confirmed by Belloche et al. in 2008 (Belloche et al. 2008) in $\operatorname{Sgr}(\mathrm{B} 2)$, where the authors were able to derive a column density of $2.8 \times 10^{16}$ molecule $\mathrm{cm}^{-2}$. For the ISM, aminoacetonitrile can be considered as a complex organic molecule, and the best hypothesis for its formation is onto icy grains (Requena-Torres et al. 2006). Then it can be released in the gaseous phase of the ISM through different processes (Burke \& Brown 2010).
Dust particles in dense clouds are made by icy mantles that surround silicate cores. Ices are mainly composed of water $\left(\mathrm{H}_{2} \mathrm{O}\right)$ with other molecules such as carbone monoxide $(\mathrm{CO})$, carbon dioxide $\left(\mathrm{CO}_{2}\right)$, ammonia $\left(\mathrm{NH}_{3}\right)$, and methanol $\left(\mathrm{CH}_{3} \mathrm{OH}\right)$ (Dartois 2005). The ISM is a harsh environment where dust is subjected to energetic processes such as thermal effects, highenergy particles and photons. According to this, different ways of aminoacetonitrile formation on the interstellar grains has been proposed (Fig. 1).

Photochemical pathways have been studied from acetonitrile and $\mathrm{NH}_{3}$ mixtures, which leads to low yields (Danger et al. 2011b). Thermal pathways from methanimine and HCN mixed with $\mathrm{NH}_{3}$ are more efficient, see Danger et al. (2011a). This study showed that the Strecker synthesis can occur in condensed phase in astrophysical-like conditions, until the aminoacetonitrile formation, as was predicted by theoretical works (Woon 2002; Koch et al. 2008). The last step of this synthesis is the AAN hydrolysis, which leads to glycine formation. This step seems to be inefficient in ISM-like conditions. Therefore, AAN is, at least, a reservoir molecule.

Bernstein et al. (2004a) have shown that AAN is also more resistant to ultraviolet (UV) and vacuum ultra-violet (VUV) lights than amino acids, with an approximate half-life in argon matrix of 1300 years under a typical UV flux for diffuse ISM, which emphasizes this role of reservoir molecule. Few studies characterize the AAN spectrally. In 2004, Bernstein et al. (2004b) published a rare gas matrix isolation study of AAN, showing that the more characteristic feature in infrared (IR), the 


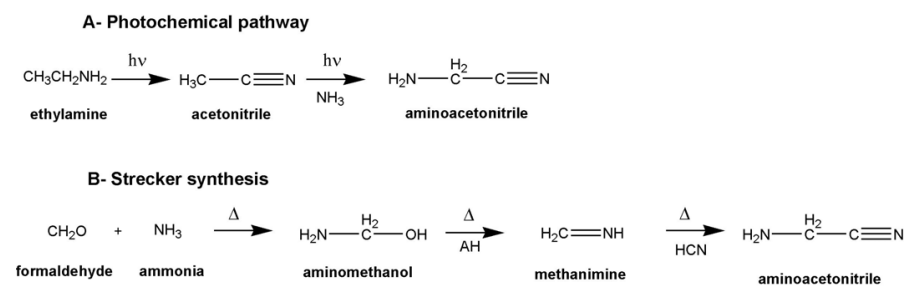

Fig. 1. Photochemical and thermal pathways for AAN formation in interstellar ices.

$v \mathrm{CN}$ stretching mode, is almost undetectable. The consequence is that the upper-limit detection in the solid phase of the ISM should be really high.

In this contribution, we provide a full characterization of solid AAN in an astrophysical environment. First we give the full IR spectrum of condensed AAN. We also propose a mass spectrometry characterization of the AAN ice with an estimation of the desorption energy of solid AAN, obtained by temperatureprogrammed desorption (TPD). We mixed AAN in $\mathrm{H}_{2} \mathrm{O}$ at $20 \mathrm{~K}$, forming an ice, and we studied the environment influence of water molecules on the characteristic $v \mathrm{CN}$ stretching mode, allowing us to derive an upper-limit detection of AAN in the interstellar ices. We then studied the reactivity of AAN with $\mathrm{CO}_{2}$ as well as its photoreactivity in the VUV range by characterizing the main photoproducts at low temperature.

\section{Experimental}

Pure $(97 \%)$ aminoacetonitrile $\left(\mathrm{NH}_{2} \mathrm{CH}_{2} \mathrm{CN}\right)$ was provided by Sigma Aldrich, and $\mathrm{CO}_{2}(99.995 \%)$ by Air Liquide. Gas mixtures were prepared by standard manometric techniques in a vacuum line under $10^{-3}$ mbar and deposited on a gold-platted surface cooled at $20 \mathrm{~K}$ by a $21 \mathrm{CTI}$ cold head in a cryostat. The temperature was controlled by a Lakeshore model 331 temperature controller, and generally a ramp of $5 \mathrm{~K} \cdot \mathrm{min}^{-1}$ was used. Our diagnosis was made with FTIR spectroscopy used in reflection mode, all spectra were recorded between 4000 and $600 \mathrm{~cm}^{-1}$ with a $1 \mathrm{~cm}^{-1}$ resolution using a NICOLET MAGNA $750 \mathrm{spec}-$ trometer equipped with a MCT (Mercury-Cadmium-Telluride) detector. One hundred interferrograms were recorded for all reference spectra and only 20 accumulations were made each $10 \mathrm{~K}$ during a warming-up. The VUV irradiation source was a $\mathrm{H}_{2}$ flux lamp irradiating in a range from $120 \mathrm{~nm}$ until a continuum in the visible through a $\mathrm{MgF}_{2}$ window directly connected to our cryostat. The VUV flux was $2 \times 10^{15}$ photons $\mathrm{cm}^{-2} \mathrm{~s}^{-1}$, which is $10^{10}$ times higher than the flux of cosmic-ray-induced UV photons existing in the dense molecular clouds of the ISM (Prasad \& Tarafdar 1983). The mass spectra were recorded with an RGA (residual gas analyzer) quadrupole mass spectrometer (MKS Microvision-IP Plus) when the sample desorbed during a temperature ramp. The ionization source was a $70 \mathrm{eV}$ electronic impact and the detector was an electron amplifier. All mass spectra were recorded in full scan mode or a SIM mode between $\mathrm{m} / \mathrm{z} 1$ and $80 \mathrm{amu}$. All samples were made in a pyrex vacuum line, each liquid (aminoacetonitrile and water) was distilled directly on the line after a few freeze-thaw cycles. Gas samples were directly used as supplied.

\section{Results}

\subsection{IR spectroscopy characterization of aminoacetonitrile}

Figure 2 displays the aminoacetonitrile IR spectrum deposited at $130 \mathrm{~K}$ to avoid any residual $\mathrm{CO}_{2}$ contamination, then recorded

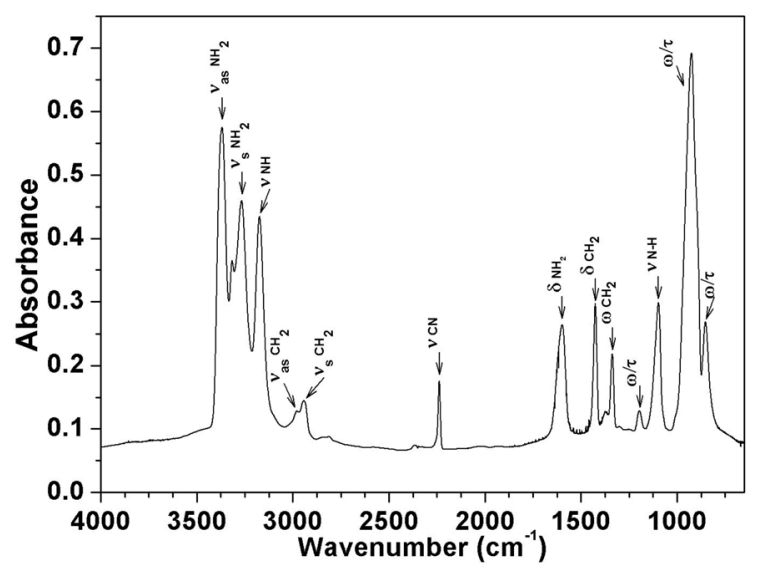

Fig. 2. FTIR spectrum of pure aminoacetonitrile deposited at $130 \mathrm{~K}$ and then recorded at $20 \mathrm{~K}$.

at $20 \mathrm{~K}$. Indeed, aminoacetonitrile and $\mathrm{CO}_{2}$ thermally react in ice for temperatures higher than $130 \mathrm{~K}$, leading to the formation of a carbamate (see Sect. 3.4). Table 1 summarizes the main wavenumbers. Basically, the main bands are the $\mathrm{NH}$ stretching and a torsion mode at $923 \mathrm{~cm}^{-1}$. The most characteristic band of the aminoacetonitrile, which is not the most intense of the spectrum, is the feature at $2237 \mathrm{~cm}^{-1}$, a typical position for a $v \mathrm{CN}$ mode. The relative intensity of this mode is quite low. Bernstein et al. (2004b) found that this mode was almost undetectable in matrix isolation experiment. In the solid phase, this mode is observable. Even if its intensity is quite low compared to the other bands, this nitrile stretching mode is used as a probe of AAN presence. Indeed, when AAN is mixed with other compounds (such as $\mathrm{H}_{2} \mathrm{O}, \mathrm{NH}_{3}$, for examples) the other AAN modes are in overlapped zones. Moreover, this spectrum area (2000$2300 \mathrm{~cm}^{-1}$ ) is generally clear and can be used for the aminoacetonitrile identification (Danger et al. 2011a). Since temperature can influence IR profiles, the AAN warming was investigated. During an annealing experiment with a $5 \mathrm{~K} / \mathrm{min}$ temperature ramp, no significant modification were observed in band positions. A sharpening appears after $160 \mathrm{~K}$ due to its crystallization. The nitrile band is shifted toward the high wavenumber of $2 \mathrm{~cm}^{-1}$ from $160 \mathrm{~K}$, and the shape of the IR profile is also sharpened from this temperature. After $190 \mathrm{~K}$, the aminoacetonitrile begins to desorb, and at $210 \mathrm{~K}$ no more compound is left on the surface.

\subsection{Mass spectrometry study and desorption of pure $\mathrm{NH}_{2} \mathrm{CH}_{2} \mathrm{CN}$ in the multilayer regime}

Figure 3 displays the mass spectrum obtained when aminoacetonitrile is desorbing around $200 \mathrm{~K}$. The main fragments are summarized in Table 2, and the most characteristic ions are $m / z$ $56 \mathrm{amu}$, aminoacetonitrile molecular ion, and the fragments $\mathrm{m} / \mathrm{z}$ 55 and 53 amu corresponding to the loss of successive $\mathrm{H}$ atoms.

Temperature-programed desorption experiments were performed to determine the activation desorption energy of AAN. Pure $\mathrm{NH}_{2} \mathrm{CH}_{2} \mathrm{CN}$ was deposited at $130 \mathrm{~K}$, then cooled down at $20 \mathrm{~K}$ on the gold surface to obtain a multilayer sample of $\mathrm{NH}_{2} \mathrm{CH}_{2} \mathrm{CN}$. Using the column density derived from the IR band at $2237 \mathrm{~cm}^{-1}$, we can estimate that the sample thickness is of approximately 800 monolayers. The solid $\mathrm{NH}_{2} \mathrm{CH}_{2} \mathrm{CN}$ sample was submitted to a temperature ramp. The TPD curve of $\mathrm{NH}_{2} \mathrm{CH}_{2} \mathrm{CN}$ given by the QMS (quadrupole mass spectrometer) signal exhibits a zeroth-order thermal desorption pattern, characteristic 
F. Borget et al.: Aminoacetonitrile characterization

Table 1. IR spectra for pure $\mathrm{NH}_{2} \mathrm{CH}_{2} \mathrm{CN}$ at $25 \mathrm{~K}$ and after 240 min of irradiation at $25 \mathrm{~K}$ in our laboratory conditions.

\begin{tabular}{|c|c|c|c|c|}
\hline Ice & Wavenumbers $\left(\mathrm{cm}^{-1}\right)$ & Assignment & Identification & Ref. \\
\hline Aminoacetonitrile & 3366 & $v_{a s}\left(\mathrm{NH}_{2}\right)$ & & \multirow{14}{*}{ Danger et al. (2011a) } \\
\hline $\mathrm{NH}_{2} \mathrm{CH}_{2} \mathrm{CN}$ & 3315 & & & \\
\hline \multirow[t]{12}{*}{ Pure, $25 \mathrm{~K}$} & 3265 & $v(\mathrm{NH})$ & & \\
\hline & 3173 & $v_{s}\left(\mathrm{NH}_{2}\right)$ & & \\
\hline & 2981 & $v_{a s}\left(\mathrm{CH}_{2}\right)$ & & \\
\hline & 2935 & $\left.v_{s} \mathrm{CH}_{2}\right)$ & & \\
\hline & 2237 & $v(\mathrm{CN})$ & & \\
\hline & 1597 & $\delta\left(\mathrm{NH}_{2}\right)$ & & \\
\hline & 1423 & $\delta\left(\mathrm{CH}_{2}\right)$ & & \\
\hline & 1335 & $\omega\left(\mathrm{CH}_{2}\right)$ & & \\
\hline & 1194 & & & \\
\hline & 1094 & $v(\mathrm{C}-\mathrm{N})$ & & \\
\hline & 923 & & & \\
\hline & 850 & & & \\
\hline Aminoacetonitrile & 2222 & $v(\mathrm{CN})$ & Imminoacetonitrile & Evans et al. (1991) \\
\hline $\mathrm{NH}_{2} \mathrm{CH}_{2} \mathrm{CN}$ & 2141 & $v(\mathrm{CN})$ & Cyanogen & Blanch \& McCluskey (1995) \\
\hline After & 2063 & $v(\mathrm{CN})$ & $\mathrm{CN}^{-}$ & Danger et al. (2011a) \\
\hline $240 \mathrm{~min}$ of & 1817 & & $?$ & \\
\hline \multirow[t]{8}{*}{ VUV irradiation } & 1658 & $\delta\left(\mathrm{NH}_{2}\right)$ & $\mathrm{NH}_{4}^{+}$ & Danger et al. (2011a) \\
\hline & 1637 & $\nu(\mathrm{C}=\mathrm{N})$ & methanimine & Theule et al. (2011) \\
\hline & 1604 & $v(\mathrm{C}=\mathrm{N})$ & iminoacetonitrile & Evans et al. (1991) \\
\hline & 1452 & $\delta\left(\mathrm{CH}_{2}\right)$ & methanimine & Theule et al. (2011) \\
\hline & 1379 & $\delta(\mathrm{CH}, \mathrm{NH})$ & iminoacetonitrile & Evans et al. (1991) \\
\hline & 1218 & $\delta(\mathrm{CH}, \mathrm{NH})$ & iminoacetonitrile & Evans et al. (1991) \\
\hline & $1171-1140$ & $\tau(\mathrm{CH})$ & methanimine & Theule et al. (2011) \\
\hline & 1076 & $\omega(\mathrm{NH})$ & methanimine & Theule et al. (2011) \\
\hline
\end{tabular}

Notes. Vibration mode: stretching $(v)$, bending $(\delta)$, wagging $(\omega)$, torsion $(\tau)$.

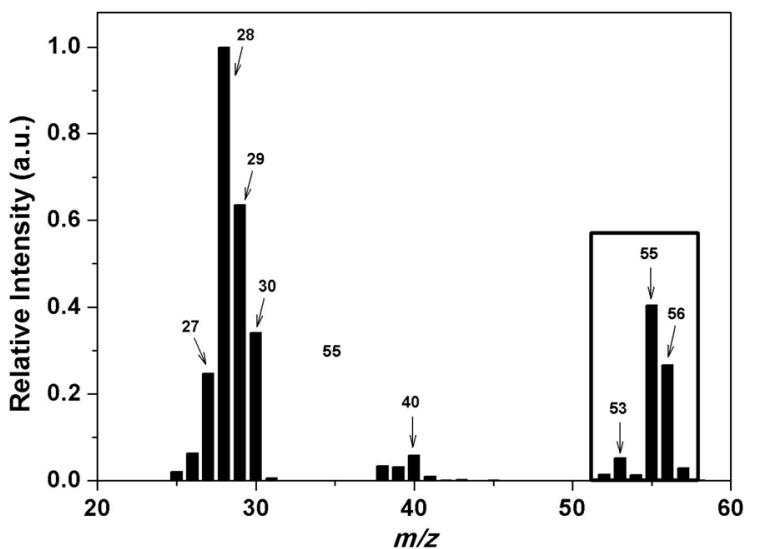

Fig. 3. Mass spectrum of AAN recorded at $204 \mathrm{~K}$ during an annealing ramp of $2 \mathrm{~K} \mathrm{~min}^{-1}$.

Table 2. Main detected fragments during the AAN desorption by mass spectrometry.

\begin{tabular}{lc}
\hline \hline$m / z(\mathrm{amu})$ & Fragments \\
\hline 56 & $\mathrm{NH}_{2} \mathrm{CH}_{2} \mathrm{CN}^{+\bullet}$ \\
55 & $\mathrm{NH}_{2}=\mathrm{CHCN}^{+}$ \\
53 & $\mathrm{NHCCN}^{+}$ \\
40 & $\mathrm{CH}_{2} \mathrm{CN}^{+}$ \\
30 & $\mathrm{NHCH}_{2}^{+}$ \\
29 & $\mathrm{NHCH}_{2}^{+}$ \\
27 & $\mathrm{NCH}^{+\bullet}$ \\
\hline
\end{tabular}

of bulk desorption in the multilayer regime, as shown in Fig. 4. Depositing five different amounts of $\mathrm{NH}_{2} \mathrm{CH}_{2} \mathrm{CN}$ give TPD curves with similar rising edge and different sharp falling edges.

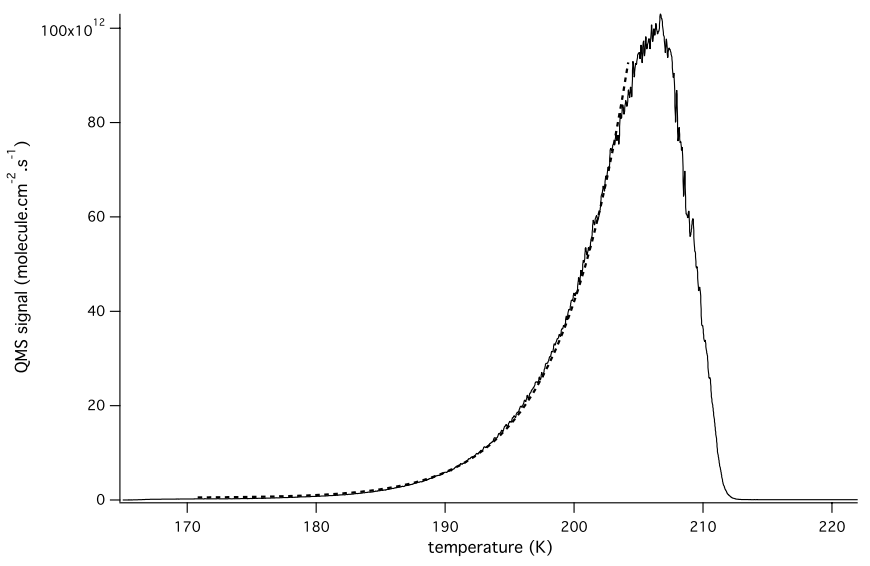

Fig. 4. Quadruple mass spectrometer temperature-programmed desorption curve $(\mathrm{m} / \mathrm{z} 56)$ of a pure $\mathrm{NH}_{2} \mathrm{CH}_{2} \mathrm{CN}$ multilayered sample with a $2 \mathrm{~K} / \mathrm{min}$ temperature ramp rate. The desorption rate was normalized to one-monolayer $\left(10^{15}\right.$ molecule $\left.\mathrm{cm}^{-2}\right)$ (dashed line). The solid line is the result of the fit by the zeroth-order Polanyi-Wigner equation.

The QMS signal is proportional to the instantaneous desorption rate. The proportionality coefficient is related to the collection efficiency and the ionization yield of the QMS. The desorption rate $\varphi$ is normalized to a one monolayer coverage $\left(10^{15}\right.$ molecule $\left.\mathrm{cm}^{-2}\right)$ and to a $1 \mathrm{~cm}^{2}$ surface by dividing by the integral of the QMS curve and multiplying by $10^{15}$ molec $\mathrm{cm}^{-2} \times 1 \mathrm{~cm}^{2}$. We fitted the rising edge of the normalized desorption rate $\varphi$ curve to the zeroth-order of the Polanyi-Wigner equation, as a function of temperature $T$ (Redhead 1962; Carter 1962):

$\varphi(T)=-\frac{\mathrm{d} N}{\mathrm{~d} T}=\frac{\nu_{0}}{\beta} \times \exp \left(-\frac{E_{\mathrm{d}}}{R \times T}\right)$, 


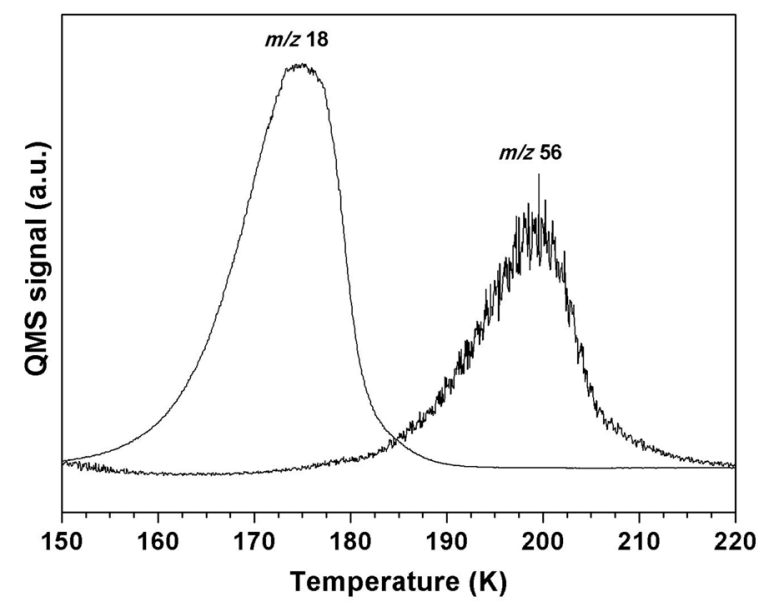

Fig. 5. Temperature desorption profile of $m / z, 18\left(\mathrm{H}_{2} \mathrm{O}\right)$ and 56 (AAN) coming from AAN $/ \mathrm{H}_{2} \mathrm{O}(1: 4)$ mixture. The ice was warmed with a $5 \mathrm{~K} \mathrm{~min}^{-1}$ heating rate.

where $v_{0}$ is the zeroth-order pre-exponential factor of the rate constant, $E_{\mathrm{d}}$ is the desorption energy, $R$ is the ideal gas constant, and $\beta$ the temperature ramp rate, $\beta$ ranging from $1 \mathrm{~K} \mathrm{~min}^{-1}$ to $8 \mathrm{~K} \mathrm{~min}^{-1}$ in our case. Since $v_{0}$ and $E_{\mathrm{d}}$ are correlated, we obtain a non physically relevant $E_{\mathrm{d}}$ by adjusting both $v_{0}$ and $E_{\mathrm{d}}$ on the TPD curve. Instead of that we chose to fix $v_{0}$ to a physically relevant value to be able to compare desorption energies of different molecules. Therefore we fixed $v_{0}$ to $10^{28}$ molecule $\mathrm{cm}^{-2} \mathrm{~s}^{-1}$ using a typical $10^{15}$ molecule $\mathrm{cm}^{-2}$ surface density of sites and a typical $10^{13} \mathrm{~s}^{-1}$ adsorbate-surface oscillation frequency. Both values can change by a small factor according to the nature of the adsorbed molecule and of the surface. The surface coverage is related to the average distance between two adsorption sites, and the oscillation frequency to the nature of the interaction between the surface and the adsorbate. The mistake on $v_{0}$ is directly correlated to the derived value of $E_{\mathrm{d}}$.

Fitting the rising edge of the TPD curve with only $E_{\mathrm{d}}$ as a free parameter and fixing $v_{0}=10^{28} \pm 0$ molecule $\mathrm{cm}^{-2} \mathrm{~s}^{-1}$, we obtain $E_{\mathrm{d}}=63.7 \pm 0.8 \mathrm{~kJ} \mathrm{~mol}^{-1}$ for the multilayer desorption of pure $\mathrm{NH}_{2} \mathrm{CH}_{2} \mathrm{CN}$. The $\pm 0.8 \mathrm{~kJ} \mathrm{~mol}^{-1}$ uncertainty on $E_{\mathrm{d}}$ is the dispersion of $E_{\mathrm{d}}$ from five different TPD experiments. The uncertainty on the fit itself or on choosing different portion of the rising edge of the TPD curve gives an approximate $0.02 \mathrm{~kJ} \mathrm{~mol}^{-1}$ uncertainty on $E_{\mathrm{d}}$. Varying the oscillation frequency from $10^{12} \mathrm{~s}^{-1}$ to $10^{14} \mathrm{~s}^{-1}$ gives $E_{\mathrm{d}}=64.5 \pm 4 \mathrm{~kJ} \mathrm{~mol}^{-1}$. So we choose to use the couple of solution $v_{0}=10^{28} \pm$ 0 molecule $\mathrm{cm}^{-2} \mathrm{~s}^{-1}, E_{\mathrm{d}}=63.7 \pm 0.8 \mathrm{~kJ} \mathrm{~mol}^{-1}$ to express the zeroth-order desorption rate of multilayer $\mathrm{NH}_{2} \mathrm{CH}_{2} \mathrm{CN}$.

\subsection{Aminoacetonitrile in water ice}

In astrophysical ices, the main component is water (Greenberg 2002), allowing a spectral window for AAN detection around $2200 \mathrm{~cm}^{-1}$ relative to the $\nu \mathrm{CN}$ mode. Therefore, in this section we estimate the influence of water on the IR profile of the nitrile mode. For this study, different ratios of $\left(\mathrm{AAN} / \mathrm{H}_{2} \mathrm{O}\right)$ mixture were deposited with ranges varying from 2:1 to 1:100. Firstly, a mixture of AAN/ $\mathrm{H}_{2} \mathrm{O}$ with 1:4 ratio was deposited, and its thermal evolution was monitored by IR spectroscopy and mass spectrometry. Figure 5 displays the corresponding mass spectrum. Two mass peaks are observed, corresponding to water and AAN desorption characterized by the ions $\mathrm{m} / \mathrm{z}, 18$ and $\mathrm{m} / \mathrm{z} 56 \mathrm{amu}$, respectively. These desorptions are independent, and correspond

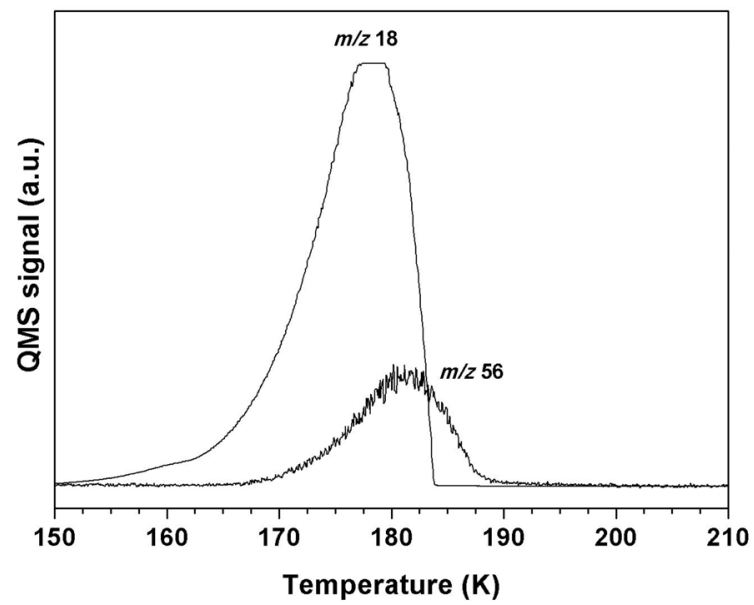

Fig. 6. Temperature desorption profile of $m / z, 18\left(\mathrm{H}_{2} \mathrm{O}\right)$ and 56 (AAN) coming from AAN/ $\mathrm{H}_{2} \mathrm{O}$ mixture (1:100). The ice was warmed with a $5 \mathrm{~K} \mathrm{~min}^{-1}$ heating rate.

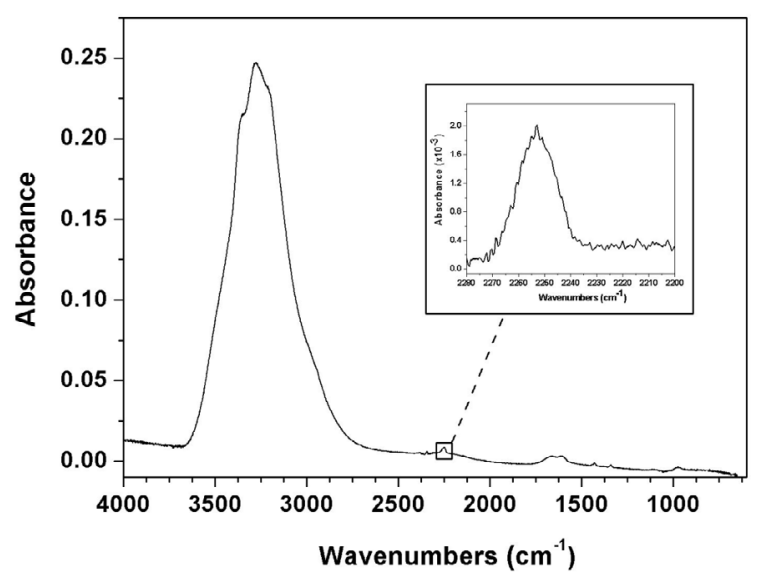

Fig. 7. FTIR spectrum of an $\mathrm{AAN} / \mathrm{H}_{2} \mathrm{O}$ ice mixture (1:3) deposited and recorded at $50 \mathrm{~K}$.

to the mass signal of each isolated molecule. It means that in this proportion, the water does not carry away the AAN.

Nevertheless, when the $\mathrm{H}_{2} \mathrm{O} / \mathrm{AAN}$ ratio was increased, AAN molecules were increasingly surrounded by water molecules. For an initial ice mixture containing $\mathrm{AAN} / \mathrm{H}_{2} \mathrm{O}$ with a ratio $1 / 100$, the AAN desorbs at $180 \mathrm{~K}$ (Fig. 6, $\mathrm{m} / \mathrm{z} 56 \mathrm{amu}$ ), which is the water desorption temperature (Fig. 6, $\mathrm{m} / \mathrm{z} 18 \mathrm{amu}$ ). Therefore at high dilution the energy desorption of AAN is equivalent to that of the major ice compound, that is in our case the water.

We also studied the influence of water on the AAN IR spectra, and more especially on the nitrile mode, since this mode is considered as a probe for AAN identification. Figure 7 displays the IR spectrum of an $\mathrm{AAN} / \mathrm{H}_{2} \mathrm{O}$ ice mixture within a $1: 3$ ratio deposited at $50 \mathrm{~K}$. The IR spectrum is largely dominated by the strong band related to the $\mathrm{OH}$ stretching mode of water, while the CN stretching mode of AAN located at $2253 \mathrm{~cm}^{-1}$ is almost undectable and shifted from the value observed in the pure solid $\left(2237 \mathrm{~cm}^{-1}\right)$. Changes are also observed during the ice warming. This mode is shifted at $170 \mathrm{~K}$, toward lower wavenumbers at $2240 \mathrm{~cm}^{-1}$ (Fig. 8B). At $180 \mathrm{~K}$, when water begins to massively desorb, the nitrile mode is shifted at $2237 \mathrm{~cm}^{-1}$ corresponding to a pure AAN ice (Figs. 8A, and C).

Moreover, in the same figure we observed that the intensity of this mode is growing during the water desorption. The main change is observed between $170 \mathrm{~K}$ and $180 \mathrm{~K}$. At this mixing 


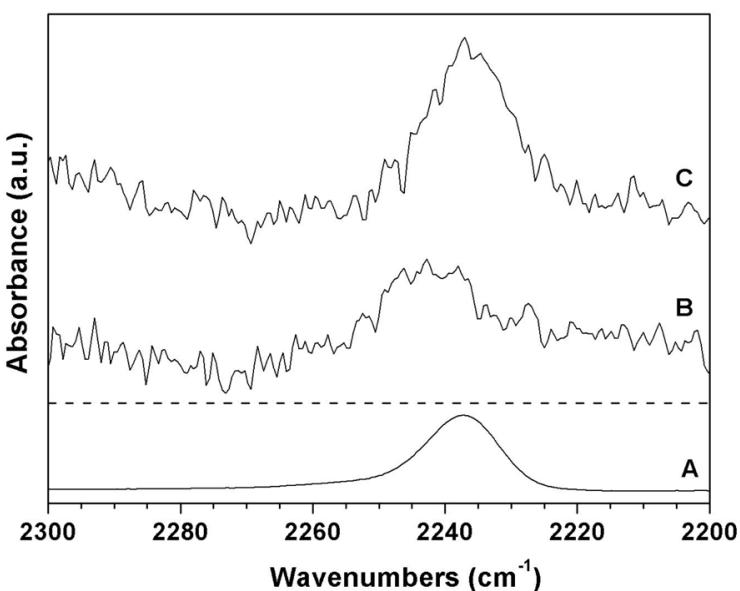

Fig. 8. $\mathrm{AAN} / \mathrm{H}_{2} \mathrm{O}(1: 3) \mathrm{IR}$ spectrum in the $\nu \mathrm{CN}$ region at (A) pure AAN at $130 \mathrm{~K}$, (B) $170 \mathrm{~K}$, and (C) $180 \mathrm{~K}$.

ratio $\left(\mathrm{AAN} / \mathrm{H}_{2} \mathrm{O}\right.$ 1:3), $\mathrm{AAN}$ and water desorption are independent (Fig. 5), which suggests that the amount of AAN is sensibly the same on the substrate at $170 \mathrm{~K}$ (before the water desorption) and at $180 \mathrm{~K}$ (after the water desorption). Therefore, considering that the absorbance $\left(A_{v}\right)$ is proportional to the column density $N\left(\right.$ molec $\left.\mathrm{cm}^{-2}\right)$ and to the band strength $\mathcal{A}$ of the $v \mathrm{CN}$ mode $\left(\mathrm{cm} \mathrm{molecule}{ }^{-1}\right)$, the water molecule effects on the nitrile vibration can be estimated using the relation $N_{x}=\frac{2.3 \times \int A_{\nu} \mathrm{d} v}{2 \times \mathcal{A}_{x}}$. Fixing the integration range between 2280 and $2225 \mathrm{~cm}^{-1}$, and reporting the ratio between the areas at 170 and $180 \mathrm{~K}$, the following correspondence is obtained: $\frac{\int A_{v}(170 K) \mathrm{d} v}{\int A_{v}(180 K) \mathrm{d} v}=\frac{\mathcal{A}_{\mathrm{AAN} / \mathrm{H}_{2} \mathrm{O}}}{\mathcal{A}_{\mathrm{AAN}}}$. To our knowledge, the nitrile band strength of the AAN has not been evaluated so far, therefore in first approximation, the band strength of the acetonitrile $(\mathrm{ACN})$ was used $\left(\mathcal{A}_{\mathrm{AAN}}=\mathcal{A}_{\mathrm{ACN}}=\right.$ $2.2 \times 10^{-18} \mathrm{~cm}$ molecule $\left.{ }^{-1}\right)$. Then, by interaction with water molecules for this mode, we obtained the value $\mathcal{A}_{\left(\mathrm{AAN} / \mathrm{H}_{2} \mathrm{O}\right)}=$ $1.1 \times 10^{-18} \mathrm{~cm}$ molecule ${ }^{-1}$. Therefore, the presence of water in AAN environment has a strong influence on the band strength, since it decreased by half. In our experimental conditions, using IR spectroscopy, we also estimated the limit of AAN dectection. The noise was estimated from the base line of our IR spectra in a zone where no main bands are observed (between 1900 and $2000 \mathrm{~cm}^{-1}$ ). Assuming that the nitrile band located at $2240 \mathrm{~cm}^{-1}$ cannot be detected for a signal-to-noise ratio $(\mathrm{S} / \mathrm{N})$ lower than 3 , we estimated that AAN cannot be detected for a column density lower than $1 \times 10^{16}$ molecule $\mathrm{cm}^{-2}$ (our typical IR spectra are averaged over 100 scans).

\subsection{Reactivity of aminoacetonitrile with $\mathrm{CO}_{2}$}

The carbon dioxide $\mathrm{CO}_{2}$ is a molecule that is suspected to have abundances (Ehrenfreund \& Charnley 2000; Pontoppidan et al. 2008) in interstellar ices between 7 and 25\%. Moreover, it has been shown recently that $\mathrm{CO}_{2}$ could react thermally into ices with methylamine to form the methylammonium methylcarbamate, which can be then isomerized into glycinate salt, the anionic form of Gly (Bossa et al. 2008b, 2009a, 2010). This way of Gly formation is an alternative way to the Strecker synthesis for the amino acid formation (Danger et al. 2011a). Since carbon dioxide can react with amine, the AAN reactivity was studied in its presence.

Figure 9 displays IR spectra of AAN diluted in carbon dioxide ice at various temperatures. The binary ice obtained at $50 \mathrm{~K}$

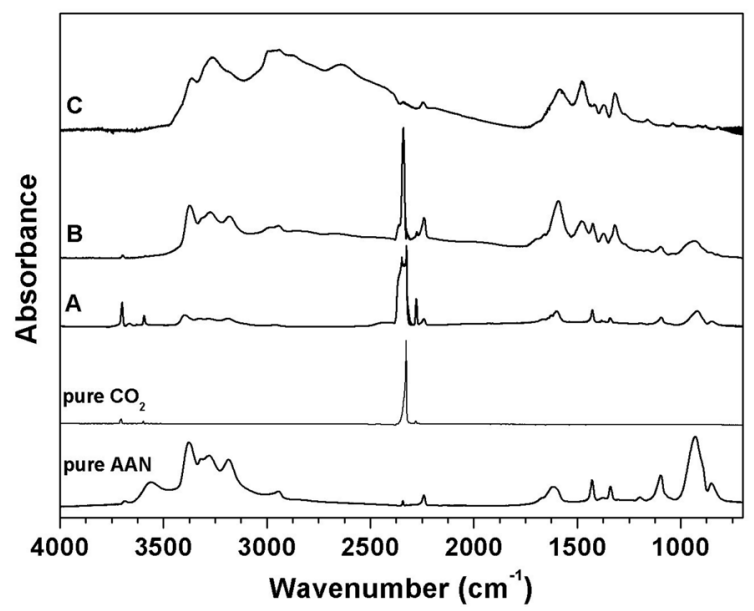

Fig. 9. IR spectra of pure aminoacetonitrile at $50 \mathrm{~K}$, pure $\mathrm{CO}_{2}$ at $25 \mathrm{~K}$, (A) $\mathrm{AAN} / \mathrm{CO}_{2} 1: 3$ at $50 \mathrm{~K}$, and after the warming of ice at (B) $130 \mathrm{~K}$, and $(\mathrm{C}) 240 \mathrm{~K}$.

Table 3. IR absorption bands and assignments of the carbamate $\mathrm{NCCH}_{2} \mathrm{NHCOO}^{-} \mathrm{NCCH}_{2} \mathrm{NH}_{3}^{+}$formed from the warming of a binary ice mixture $\mathrm{NH}_{2} \mathrm{CH}_{2} \mathrm{CN}: \mathrm{CO}_{2}=1: 3$.

\begin{tabular}{lc}
\hline \hline Assignment & $\begin{array}{r}\text { Wavenumbers } \\
\left(\mathrm{cm}^{-1}\right)\end{array}$ \\
\hline$v\left(\mathrm{NH}_{2}\right)$ & 3367 \\
$v\left(\mathrm{NH}_{2}\right)$ & 3264 \\
$v(\mathrm{CH})$ & 2996 \\
$v(\mathrm{CH})$ & 2942 \\
$v(\mathrm{CH})$ & 2856 \\
$v\left(\mathrm{NH}_{3}^{+}\right)$ & 2619 \\
$v(\mathrm{CN})$ & 2245 \\
$v(\mathrm{CN})$ & 2108 \\
$v_{a s}\left(\mathrm{COO}^{-}\right)$ & 1574 \\
$\delta\left(\mathrm{NH}_{3}^{+}\right)$ & 1474 \\
$\delta(\mathrm{CH})$ & 1417 \\
$\left.v_{s}(\mathrm{COO})^{-}\right)$ & 1363 \\
$\delta(\mathrm{CH})$ & 1308 \\
$v(\mathrm{CN})$ & 1154 \\
$\rho(\mathrm{NH})$ & 1027 \\
$\delta_{\text {oop }}(\mathrm{NH})$ & 976 \\
$\delta_{\text {oop }}(\mathrm{NH})$ & 905 \\
\hline
\end{tabular}

Notes. Vibration mode: stretching $(v)$, bending $(\delta)$, rocking $(\rho)$, out of plane deformation $\left(\delta_{\text {oop }}\right)$.

(Fig. 9A) is the superposition of pure $\mathrm{CO}_{2}$, and pure AAN (Fig. 9) spectra, indicating that no reaction occurs at $50 \mathrm{~K}$. When the temperature was increased, new bands appear on the spectrum recorded at $130 \mathrm{~K}$ (Fig. 9B), while at the same time, the characteristic bands of AAN and $\mathrm{CO}_{2}$ decreased, which indicates a thermal reaction between them. Finally at $240 \mathrm{~K}$, since the remaining starting materials $\left(\mathrm{AAN}\right.$ and $\left.\mathrm{CO}_{2}\right)$ have desorbed, we observe the IR spectrum of the pure product (Fig. 9C). The observed IR bands are very close to those already observed for $\mathrm{CO}_{2}$ reactivity with amines (Bossa et al. 2008a,b), and are listed in Table 3. Those bands are characteristic of the corresponding carbamate $\left(\mathrm{NC}-\mathrm{CH}_{2}-\mathrm{NH}-\mathrm{COO}^{-}\right)$and its counter-ion, which is the ammonium salt of AAN $\left(\mathrm{NC}-\mathrm{CH}_{2}-\mathrm{NH}_{3}^{+}\right)$. Finally, the carbamate fully sublimates in our experimental conditions at temperature higher than $270 \mathrm{~K}$ (Fig. 10). The reaction between $\mathrm{AAN}$ and $\mathrm{CO}_{2}$ can be summarized by the following equation:

$2 \mathrm{NH}_{2} \mathrm{CH}_{2} \mathrm{CN}+\mathrm{CO}_{2} \rightarrow \mathrm{NCCH}_{2} \mathrm{NHCOO}^{-} \mathrm{NCCH}_{2} \mathrm{NH}_{3}^{+}$. 


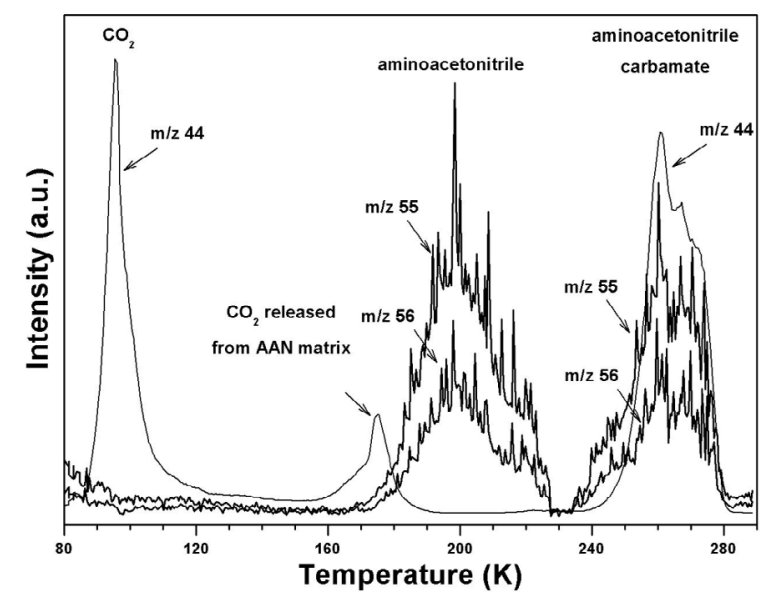

Fig. 10. Mass spectrum obtained during the warming of an initial ice containing $\mathrm{AAN} / \mathrm{CO}_{2}$ 1:3.

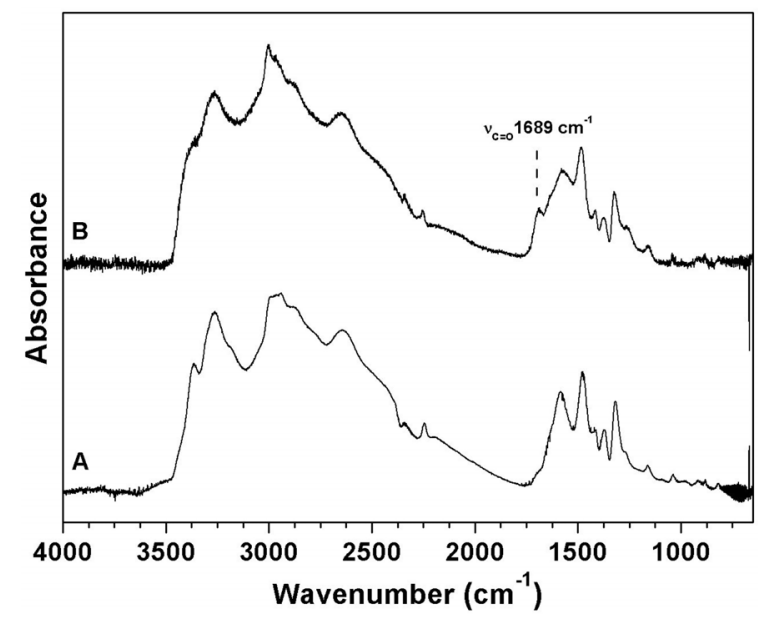

Fig. 11. IR spectra obtained at $240 \mathrm{~K}$ after the warming of an initial ice containing (A) AAN/CO $1: 3$, and (B) AAN $/ \mathrm{CO}_{2} / \mathrm{H}_{2} \mathrm{O}$ 1:3:3.

The carbamate formation is also supported by a mass spectrometry experiment showing first the desorption of the remaining starting materials: $\mathrm{CO}_{2}$ at $100 \mathrm{~K}$ followed by the AAN at $200 \mathrm{~K}$. At $260 \mathrm{~K}$, we then observe three masses $\mathrm{m} / \mathrm{z}$ 44, 55, $56 \mathrm{amu}$ (Fig. 9) when the carbamate starts to sublimate. Those masses are characteristic of AAN $(\mathrm{m} / \mathrm{z}, 56$ and $55 \mathrm{amu})$ and $\mathrm{CO}_{2}(\mathrm{~m} / \mathrm{z}$ $44 \mathrm{amu}$ ), and can be easily explained by the decomposition of the carbamate in the gas phase, into $\mathrm{CO}_{2}$ and AAN.

We also investigated the influence of water on the warming of this ice mixture. We diluted $\mathrm{AAN} / \mathrm{CO}_{2}$ in water to obtain an ice mixture $\mathrm{AAN} / \mathrm{CO}_{2} / \mathrm{H}_{2} \mathrm{O}$ within a 1:3:3 molecular ratio. After thermal treatment at $240 \mathrm{~K}$, the same type of residue is observed (Fig. 11) for both AAN/CO $/$ (Fig. 11A) and AAN $/ \mathrm{CO}_{2} / \mathrm{H}_{2} \mathrm{O}$ (Fig. 11B). Slight differences are observed, which correspond to the balance between neutral carbamic acid $\left(\mathrm{NCCH}_{2} \mathrm{NHCOOH}\right)$ characterized by a band located at $1689 \mathrm{~cm}^{-1}$ and ionic carbamate $\left(\mathrm{NCCH}_{2}-\mathrm{NHCOO}^{-}\right)$(Fig. 11). In water, it seems that more carbamic acid is formed. These experiments generalize the formation of carbamate derivative through the possible formation and reaction of amines and $\mathrm{CO}_{2}$ at low temperature in interstellar ice analogues.

\subsection{VUV irradiation}

Since VUV irradiations can occur in various astrophysical environments, we also studied the photoreactivity of AAN. For

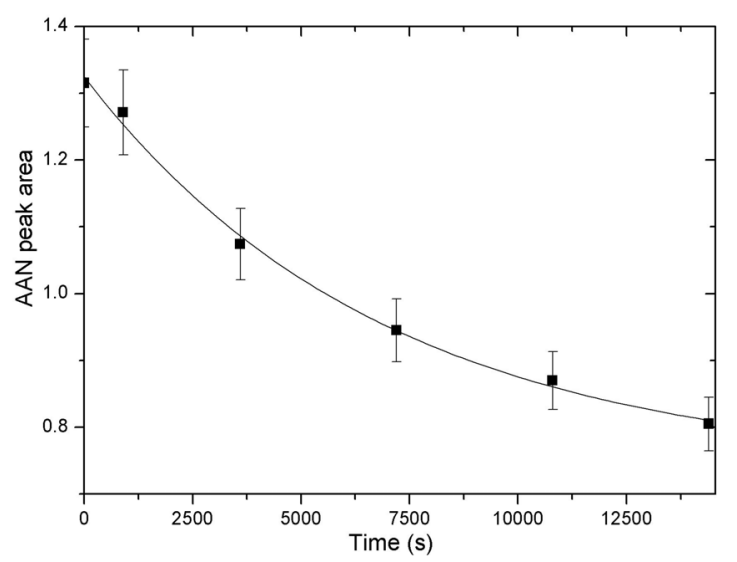

Fig. 12. Diminishing area of the IR feature of AAN $\left(2237 \mathrm{~cm}^{-1}\right)$ with increasing the VUV exposure. The decrease of AAN is fitted against an exponential decay.

this study, pure AAN was deposited in the cryostat on the gold surface and was irradiated. In the laboratory time scale, this VUV irradiation of AAN is not very efficient and the photoproducts bands that are growing have low intensities. Figure 12 shows the decay of the AAN nitrile band at $2237 \mathrm{~cm}^{-1}$ integrated between 2280 and $2225 \mathrm{~cm}^{-1}$ using the band strength of standard nitrile containing molecules (acetonitrile: $\mathcal{A}_{\mathrm{AAN}}=$ $\mathcal{A}_{\mathrm{ACN}}=2.2 \times 10^{-18} \mathrm{~cm}$ molecule $\left.{ }^{-1}\right)$. After $4 \mathrm{~h}$ of irradiation, $40 \%$ of AAN was consumed, as shown in Fig. 12. Its disappearance was fitted by a first-order decay (simple exponential: $\left.y=0.587 \times \exp \left(-1.446 \times 10^{-4} \times t\right)+0.838\right)$, allowing us to derive a photo-dissociation cross section of $7.2 \times 10^{-20}$ photon $^{-1} \mathrm{~cm}^{2}$, which agrees with the value of $8.8 \times 10^{-20}$ photon $^{-1} \mathrm{~cm}^{2}$ reported by Bernstein et al. (2004a). This cross-section is one order of magnitude lower than the typical values reported for typical molecules observed in the interstellar ices $\left(\mathrm{CH}_{3} \mathrm{OH}, \mathrm{CO}_{2}\right.$, $\mathrm{NH}_{3}$ ), which supports the hypothesis that AAN can survive in presolar environment and so be incorporated into a newly forming planetary system. Thus the photochemical stability of AAN, combined with its capacity to form Gly in liquid water, make AAN a logical precursors to Gly in meteorites (Bernstein et al. 2004a).

Figure 13 displays the difference spectrum of two spectra obtained before and after $258 \mathrm{~min}$ of VUV irradiation. The most striking feature is growing in the $2087-2060 \mathrm{~cm}^{-1}$ zone, and according to its width as well as its structure, this band should be related to molecules bearing a $\mathrm{CN}$ moiety. The bands, which are growing at 2222, 1604, 1379 and $1218 \mathrm{~cm}^{-1}$, correspond to the iminoacetonitrile, $\mathrm{HN}=\mathrm{CH}=\mathrm{CN}$ (Fig. 13) (Evans et al. 1991). These assignments are also confirmed by the presence of bands at 2141 and $2063 \mathrm{~cm}^{-1}$ caused by the photodecomposition of iminoacetonitrile in cyanogen, NC-CN (Blanch \& McCluskey 1995). Indeed, this product is due to the dehydrogenation of the iminoacetonitrile, which is a common process for the VUV irradiation (Bossa et al. 2012).

The bands at 1637 and $1452 \mathrm{~cm}^{-1}$ are caused by the formation of the methanimine, $\mathrm{CH}_{2}=\mathrm{NH}$ (Fig. 13) (Danger et al. 2011a; Theule et al. 2011). This product is probably formed by a cleavage of the $\mathrm{C}-\mathrm{C}$ bond of the iminoacetonitrile forming the radical $\mathrm{HN}=\mathrm{CH}^{\circ}$, which can react with an $\mathrm{H}$ radical, forming the methanimine. The dehydrogenation product of this latter molecule is the HCN formation, which is not directly detected in our experiments. But the $\mathrm{CN}^{-}$and its counter-ion $\mathrm{NH}_{4}^{+}$ are detected with the bands at $2063\left(\mathrm{CN}^{-}\right), 1658 \mathrm{~cm}^{-1}\left(\mathrm{NH}_{4}^{+}\right)$, 


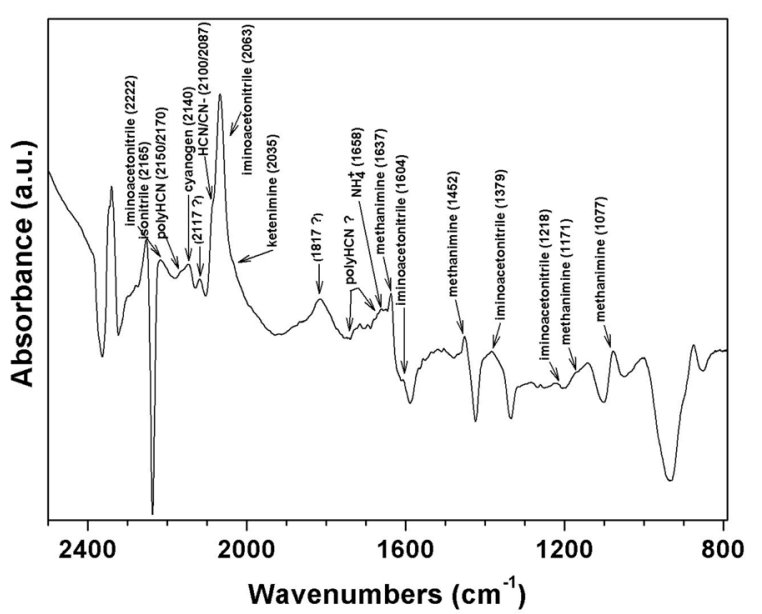

Fig. 13. Difference of IR spectra obtained at $25 \mathrm{~K}$ before and after 258 min of VUV irradiation containing pure AAN.

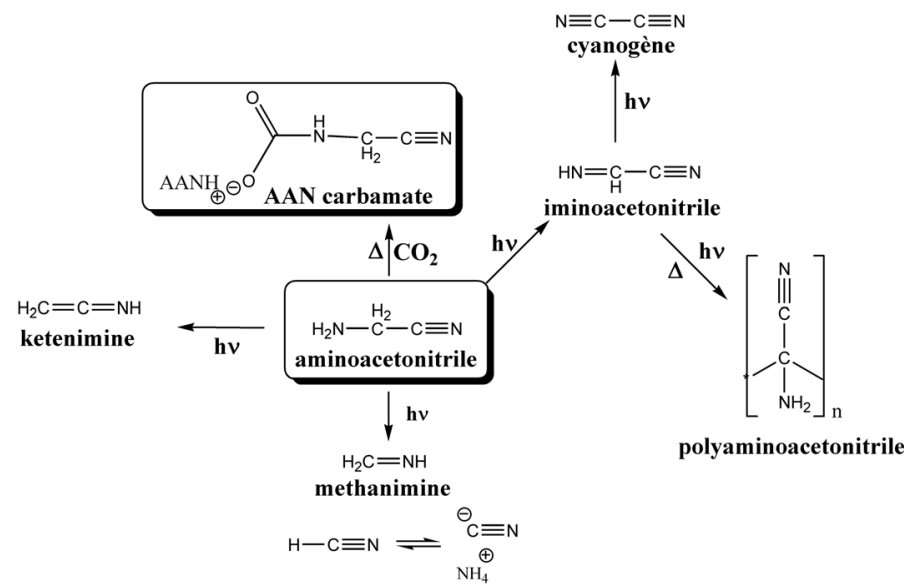

Fig. 14. Representation of the different possible pathways of degradation of AAN and its carbamate under VUV irradiations.

which are typical for the acid-base reaction induced by $\mathrm{HCN}$ (Danger et al. 2011a; Moore \& Hudson 2003; Gerakines et al. 2004; Clutter \& Thompson 1969). When the resulting irradiated ice is warmed, a nitrile band at $2161 \mathrm{~cm}^{-1}$ appears (Fig. 12B). This band is the signature of an iminoacetonitrile polymerization (Lorencak et al. 1986; Khare et al. 1994; Liebman et al. 1995). The different degradation pathways of aminoacetonitrile are summarized in Fig. 14.

\section{Astrophysical implication}

AAN can be considered as a glycine precursor in astrophysical environments because of its central place in the Strecker synthesis. Recently it has been shown that the first steps of this synthesis could take place in interstellar environment (Danger et al. 2011a), and especially in the icy grains around $130 \mathrm{~K}$. These icy grains have to be considered as important chemical reactors for the molecular complexity emergence in the ISM (Herbst \& van Dishoeck 2009). Simple molecules can indeed be formed in the gas phase, and condensed onto these grains followed by reactions like hydrogenation (Theule et al. 2011), irradiations or thermal reactivity, leading to more complex molecules .

We have shown in this contribution that in our experimental conditions, in a water-dominated ice, the upper limit of AAN
Table 4. Column densities and upper limit of AAN detection in various astrophysical environments.

\begin{tabular}{lccc}
\hline \hline Column density $($ molecule cm & -2 \\
& HH 46 & NGC7538 & W33A \\
\hline$N\left(\mathrm{H}_{2} \mathrm{O}\right)^{a}$ & $8.0 \times 10^{18}$ & $6.8 \times 10^{18}$ & $9.0 \times 10^{18}$ \\
$N_{\text {limit }}(\mathrm{AAN}) / N\left(\mathrm{H}_{2} \mathrm{O}\right)^{b}(\%)$ & 6 & 7 & 9 \\
$N\left(\mathrm{CO}_{2}\right) / N\left(\mathrm{H}_{2} \mathrm{O}\right)^{a}(\%)$ & 32 & 24 & 16 \\
$N\left(\mathrm{CH}_{3} \mathrm{OH}\right) / N\left(\mathrm{H}_{2} \mathrm{O}\right)^{a}(\%)$ & 7 & 7 & 22 \\
\hline
\end{tabular}

Notes. ${ }^{(a)}$ Boogert et al. (2004). ${ }^{(b)} N_{\text {limit }}(\mathrm{AAN})$ : detection limit of AAN, assuming the $\mathrm{S} / \mathrm{N}$ of the ISO satellite is 40 times lower than ours. $N_{\text {limit }}(\mathrm{AAN})=N_{\text {limit lab }}(\mathrm{AAN}) \times 40=5 \times 10^{17}$ molecule $\mathrm{cm}^{-2}$.

detection is $1 \times 10^{16}$ molecule $\mathrm{cm}^{-2}$ using the $\mathrm{CN}$ stretching mode located around $2250 \mathrm{~cm}^{-1}$. The band strength of this mode is very low and unfortunately even lower (divided by a factor 2) when AAN is diluted in water. This implies that the aminoacetonitrile detection in the icy grains is far from obvious, since the water is the most abundant compound of the ice, and that only few amounts of aminoacetonitrile are certainly present in the ice. To illustrate the difficulty of detecting AAN by means of IR spectroscopy in ice, we estimated the upper limit of detection of AAN in various astrophysical environments, considering that the $\mathrm{S} / \mathrm{N}$ of ISO satellite is 40 times lower than ours (Table 4). For these environments, AAN would be detectable only for an AAN $/ \mathrm{H}_{2} \mathrm{O}$ ratio higher than $6 \%$. No one expects AAN to be in such high concentration in interstellar ices, which rules out the possibility of detection in ice of AAN in the mid-IR region (MIR). However, far-IR spectroscopy (FIR) may be an interesting alternative way to characterize AAN in ice.

However, in specific zones, such as in protostellar environments (Ceccarelli 2008) or hot cores, exchanges can occur between the solid phase of these icy grains and the gas phase, leading to a release of complex molecules in the gas phase allowing their detection. This is an explanation of the AAN detection in the gas phase of SgrB2 (Belloche et al. 2008), where a column density of $2.8 \times 10^{16}$ molecule $\mathrm{cm}^{-2}$ has been derived. In this study, we also measured the activation desorption energy of AAN around $63.7 \mathrm{~kJ} \mathrm{~mol}^{-1}$ for the pure solid. This value would indicate that this molecule is more refractory than water (48 $\mathrm{kJ} \mathrm{mol}^{-1}$, Fraser et al. 2001) and should be released in the gas phase at a temperature higher than water. However, when AAN is diluted in water ice, a large amount of AAN is driven away when the water starts to sublime. Consequently, in interstellar ices, AAN could be released in the gas phase at lower temperature in a hot environment such as hot cores, when the water ice sublimes. This hypothesis is supported by the fact that AAN is detected in the gas phase at $100 \mathrm{~K}$ in SgrB2 (Belloche et al. 2008), which corresponds to the snow-line temperature in the ISM. This result agrees with an AAN formation on the interstellar grains at low temperature and its release in the gas phase when water sublimes around $100 \mathrm{~K}$ in the ISM.

From an astrobiological point of view, aminoacetonitrile has to be considered as a reservoir of glycine molecules. Indeed, as shown with the experiment using $\mathrm{AAN}: \mathrm{H}_{2} \mathrm{O}$ mixtures, the Strecker synthesis could not continue until the amino acid formation as was already predicted by theoretical calculations (Rimola et al. 2010). Furthermore, because we have observed that formic acid can activate imine reactivity (Vinogradoff et al. 2012), we tested the heating of an ice mixture containing $\mathrm{AAN} / \mathrm{H}_{2} \mathrm{O} / \mathrm{HCOOH}$. We observed no glycinamide or glycine formation, but only the salt formation. Therefore, it seems that the last step of the Strecker synthesis, the glycine formation, is not effective in interstellar environments. In 
consequence, this molecule appears to be a reservoir molecule of glycine in these environments.

These icy grains containing organic matter such as aminoacetonitrile were able to continue to evolve, because they could be incorporated in the protoplanetary disk formation phase, leading to the formation of comets and asteroids. Inside these small interplanetary bodies, they are protected from additional degradations. However, in some asteroids, these organic molecules may have been subjected to an aqueous phase (Abramov \& Mojzsis 2011; Herd et al. 2011), which led to a hydrolysis process, and therefore to the glycine in the case of aminoacetonitrile. In the end, comets and asteroids were able to deliver this complex organic matter to telluric planets, where it could undergo chemical processes in specific environments, such as in prebiotic environments, meaning that the aminoacetonitrile formed in astrophysical environments may be considered as a prebiotic molecule once it is present in these specific environments, as on the primitive Earth.

\section{Conclusion}

We characterized in astrophysical-like conditions AAN, which is a central molecule in the Strecker synthesis yielding amino acids. This study demonstrated that if AAN exists in dusty grains, it should be undetectable in the solid phase by actual means of observation in the MIR region. Indeed, the main band at $2237 \mathrm{~cm}^{-1}$ is the only one that can be used as a probe. It is inconvenient that this band is very sensible to the water environment. In consequence, another part of the IR region should be studied, such as FIR region. Therefore, this molecule has to be in the gas phase to be observed, as Belloche et al. have done in SgrB2 (Belloche et al. 2008). Moreover, we demonstrated that the desorption energy is quite significant, which means that this molecule has to be in a hot region to be released to the gaseous phase. In astrophysical environments, AAN has to be considered as a reservoir molecule of glycine, but it seems almost impossible for this molecule to yield Gly in those environments. However, in a planetary system, AAN can lead to Gly formation through hydrolysis processes inside asteroids or at the surface of telluric planets.

Acknowledgements. This work has been founded by the French national program Physique Chimie du Milieu (PCMI), the French interdisciplinary program Evolution des Planètes et Origine de la Vie (EPOV) and the Centre National d'Études Spatiales (CNES).

\section{References}

Abramov, O., \& Mojzsis, S. J. 2011, Icarus, 213, 273

Belloche, A., Menten, K. M., Comito, C., et al. 2008, A\&A, 482, 179

Bernstein, M. P., Ashbourn, S. F., Sandford, S. A., \& Allamandola, L. J. 2004a, ApJ, 601, 365
Bernstein, M. P., Bauschlicher, C. W., \& Sandford, S. A. 2004b, Adv. Space Res., 33,40

Blanch, R. J., \& McCluskey, A. 1995, Chem. Phys. Lett., 241, 116

Boogert, A. C. A., Pontoppidan, K. M., Lahuis, F., et al. 2004, Ap\&SS, 154, 359

Bossa, J., Borget, F., Duvernay, F., Theule, P., \& Chiavassa, T. 2008a, J. Phys. Chem. A, 112, 5113

Bossa, J. B., Theule, P., Duvernay, F., Borget, F., \& Chiavassa, T. 2008b, A\&A, 492, 719

Bossa, J. B., Duvernay, F., Theule, P., et al. 2009a, A\&A, 506, 601

Bossa, J. B., Theule, P., Duvernay, F., \& Chiavassa, T. 2009b, ApJ, 707, 1524

Bossa, J., Borget, F., Duvernay, F., Theule, P., \& Chiavassa, T. 2010, J. Phys. Org. Chem., 23, 333

Bossa, J., Borget, F., Duvernay, F., et al. 2012, Aust. J. Chem., 65, 129

Burke, D. J., \& Brown, W. A. 2010, Phys. Chem. Chem. Phys., 12, 5947

Carter, G. 1962, Vacuum, 12, 245

Ceccarelli, C. 2008, Proc. IAU Conf., 4, 79

Clutter, D. R., \& Thompson, W. E. 1969, J. Chem. Phys., 51, 153

Commeyras, A., Taillades, J., Collet, H., et al. 2004, Orig. Life Evol. Biosph., 34,35

Danger, G., Boiteau, L., Cottet, H., \& Pascal, R. 2006, J. Am. Chem. Soc., 128, 7412

Danger, G., Borget, F., Chomat, M., et al. 2011a, A\&A, 535, A47

Danger, G., Bossa, J., de Marcellus, P., et al. 2011b, A\&A, 525, A30

Dartois, E. 2005, Space Sci. Rev., 119, 293

de Marcellus, P., Bertrand, M., Nuevo, M., Westall, F., \& Le Sergeant d'Hendecourt, L. 2011, Astrobiology, 11, 847

Duvernay, F., Dufauret, V., Danger, G., et al. 2010, A\&A, 523, A8

Ehrenfreund, P., \& Charnley, S. B. 2000, ARA\&A, 38, 427

Elsila, J. E., Dworkin, J. P., Bernstein, M. P., Martin, M. P., \& Sandford, S. A. 2007, ApJ, 660, 911

Evans, R. A., Lorencak, P., Ha, T. K., \& Wentrup, C. 1991, J. Am. Chem. Soc., 113,7261

Fraser, H. J., Collings, M. P., McCoustra, M. R. S., \& Williams, D. A. 2001, MNRAS, 327, 1165

Gerakines, P., Moore, M., \& Hudson, R. 2004, Icarus, 170, 202

Greenberg, J. M. 2002, Surf. Sci., 500, 793

Herbst, E., \& van Dishoeck, E. F. 2009, ARA\&A, 47, 427

Herd, C. D. K., Blinova, A., Simkus, D. N., et al. 2011, Science, 332, 1304

Khare, B., Sagan, C., Thompson, W., et al. 1994, Can. J. Chem., 72, 678

Koch, D. M., Toubin, C., Peslherbe, G. H., \& Hynes, J. T. 2008, J. Phys. Chem. C, 112,2972

Liebman, S., Pesce-Rodriguez, R., \& Matthews, C. 1995, Adv. Space Res., 15, 71

Lorencak, P., Raabe, G., Radziszewski, J. J., \& Wentrup, C. 1986, J. Chem. Soc., Chem. Commun., 916

Miller, S. L. 1953, Science, 117, 528

Moore, M. H., \& Hudson, R. L. 2003, Icarus, 161, 486

Pontoppidan, K., Boogert, A., Fraser, H., et al. 2008, ApJ, 678, 1005

Prasad, S. S., \& Tarafdar, S. P. 1983, ApJ, 267, 603

Redhead, P. 1962, Vacuum, 12, 203

Requena-Torres, M. A., Martn-Pintado, J., Rodrguez-Franco, A., et al. 2006, A\&A, 455, 15

Rimola, A., Sodupe, M., \& Ugliengo, P. 2010, Phys. Chem. Chem. Phys., 12, 5285

Theule, P., Borget, F., Mispelaer, F., et al. 2011, A\&A, 534, A64

Vinogradoff, V., Duvernay, F., Danger, G., Theule, P., \& Chiavassa, T. 2011, A\&A, 530, A128

Vinogradoff, V., Duvernay, F., Farabet, M., et al. 2012, J. Phys. Chem. A, 116, 2225

Woon, D. E. 2002, ApJ, 571, L177 